\title{
Efisiensi Belanja Pemerintah Terhadap Indeks Pembangunan Manusia Secara Regional di Indonesia
}

\author{
Indra Kurniawan ${ }^{* a}$, Murtala ${ }^{* b}$, Reza Juanda ${ }^{*} \mathrm{c}$ \\ *Fakultas Ekonomi dan Bisnis Universitas Malikussaleh \\ a Corresponding author : indrakurniawan0397@gmail.com \\ b murtala@unimal.ac.id \\ c juanda.reza@unimal.ac.id
}

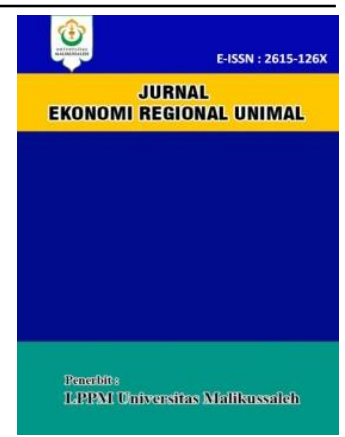

A R T I CLE IN F ORMATION

A B S T R A C T

Keywords:

Government Expenditures and

Human Development Index.
This study analyzed the efficient level for Government expenditure on the regional Human Development Index (HDI) in Indonesia in 20142018. This study used panel data with the number of DMUs in 34 provinces in Indonesia, while the input variable was government spending in the health, education, economy, social protection sectors, and the output variable was the human development index for 20142018. This study used Data Envelopment Analysis (DEA) testing and focused on input (input-oriented) by using the assumption of Variable Return to Scale (VRS). The results showed that only 14 provinces were efficient in using Government Expenditures to increase HDI, but 20 provinces were inefficient in using Government Expenditures to increase HDI. Thus it is hoped that all provinces, especially those who were inefficient, can improve their performance in the use of government expenditure budgets that have been used in increasing the HDI value and the government can make decisions or policies in the problem of achieving the HDI value for each province in Indonesia.

\section{PENDAHULUAN}

Pembangunan Manusia

(Human Development) selalu menjadi topik pembicaraan yang menarik oleh berbagai kalangan. Topik ini menarik sejak United Nations Development Programme (UNDP) mulai memperkenalkannya pada tahun 1990. Hal tersebut disebabkan karena paradigma pembangunan yang dianut sebagian besar negara di dunia selama ini yang menitikberatkan bahwa pertumbuhan ekonomi mengalami perubahan kearah paradigma baru. Paradigma baru tersebut menitikberatkan pembangunan kepada usaha untuk meningkatkan kualitas manusia dan memberikan peluang yang lebih luas pada penduduk untuk berpartisipasi dalam proses penetapan kebijakan pembangunan.

Dalam konteks pembangunan daerah, isu pembangunan manusia menjadi isu yang krusial. Hal ini mengingat perubahan paradigma pembangunan yang menitikberatkan kepada usaha untuk meningkatkan kualitas manusia belum dipahami secara komprehensif oleh daerah. Sebagian besar paradigma pembangunan

di daerah masih berorientasi pada pembangunan fisik, belum pada pembangunan manusianya.

Pembangunan manusia adalah mempunyai peranan penting dalam kemajuan suatu Negara, dikatakan maju tidak hanya dihitung dari PDB, akan tetapi juga mencakup aspek harapan hidup, pendidikan dan daya beli masyarakat (Widodo \& Waridin, 2011). Tanggung jawab moral yang harus dijawab bangsa Indonesia adalah memiliki kualitas unggul pada sumber daya manusia.

Indeks Pembangunan Manusia (IPM) merupakan indikator penting untuk mengukur keberhasilan dalam membangun kualitas hidup manusia (BPS, 2017). IPM dibentuk oleh tiga dimensi dasar yaitu; umur panjang dan sehat (along and healty life), pengetahuan (knowledge) dan standar hidup layak (decent standard of living) (BPS, 2017). Terdapat dua aspek yang perlu diperhatikan yaitu kecepatan dan status pencapaian 
untuk melihat kemajuan pembangunan manusia (BPS, 2017).

Perkembangan Indeks Pembangunan Manusia (IPM) di Indonesia mengalami peningkatan mulai tahun 2010-2018. Berikut ini tren IPM Indonesia mulai tahun 2010-2018 dapat dilihat pada gambar 1 sebagai berikut:

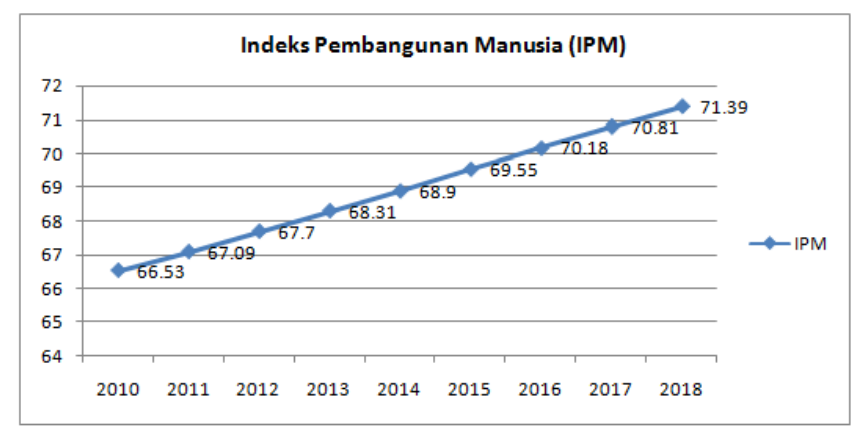

Sumber : Badan Pusat Statistik, 2020

$$
\text { Gambar } 1
$$

Tren dan Pertumbuhan Indeks Pembangunan Manusia di Indonesia Tahun 2010-2018

Berdasarkan Gambar 1 di atas dapat dilihat bahwa IPM tembus rekor tertinggi pada tahun 2018 sebesar 71,39\%, IPM naik 0,58 poin atau tumbuh sebesar $0,82 \%$ dibandingkan setahun sebelumnya (BPS, 2018). IPM Indonesia dari tahun ke tahun mengalami peningkatan, utamanya dalam kurun waktu 2010 hingga 2018. Adapun pada tahun 2010 IPM Indonesia masih sebesar $66,53 \%$ dan secara bertahap meningkat dari tahun ke tahun hingga mencapai 71,39\% pada 2018.

Berdasarkan data dari Human Development Report (HDR) peringkat Indonesia berada dibawah Singapura, Brunei Darussalam, Malaysia dan Thailand apabila kita bandingkan peringkat IPM Indonesia dengan negara ASEAN. Untuk menyelesaikan masalah tersebut, perlu kita ketahui komponen indeks apa yang dikategorikan rendah, dengan demikian pengambil kebijakan dapat menentukan prioritas untuk meningkatkan nilai IPM Indonesia.

Pada penelitian ini, penulis akan berfokus pada efisiensi belanja pemerintah terhadap indeks pembangunan manusia secara regional di Indonesia dengan menggunakan metode analisis data non-parametrik yaitu Data Envelopment Analysis (DEA). Adapun variabel yang digunakan sebagai input yaitu bidang kesehatan, pendidikan, ekonomi dan perlindungan sosial, sedangkan yang menjadi variabel output ialah indeks pembangunan manusia.

Efisien merupakan suatu indikator dalam mengukur tingkat output dengan input serendah mungkin namun menghasilkan sesuatu hal yang baik dengan menggunakan strategi. Dalam bidang ilmu ekonomi efisiensi merupakan bentuk pemaksimalan dalam penggunaan beserta pemamfaatan sumberdaya dalam suatu aktivitas ekonomi suatu negara dalam mengoptimalkan atau mengalokasikan infut dan output negara tersebut agar terciptanya efisiensi. Output suatu negara dapat dihitung menggunakan Produk Domestik Bruto (PDB) (Said, 2014).

Dengan demikian tujuan dari penelitian ini untuk mengetahui seberapa besar tingkat efisiensi belanja pemerintah sektor kesehatan, pendidikan, ekonomi, dan perlindungan sosial. terhadap indeks pembangunan manusia secara regional di Indonesia.

Selanjutnya bagian kedua dari penelitian ini akan membahas tinjauan teoritis, metode penelitian akan dibahas pada bagian ketiga. Kemudian pada bagian ke empat akan dibahas hasil penelitian dan pembahasan. Pada bagian kelima akan membahas kesimpulan dan saran.

\section{TINJAUAN TEORITIS \\ Indeks Pembangunan Manusia}

Human Development Index (HDI) atau

Indeks Pembangunan Manusia (IPM) diperkenalkan oleh UNDP sebagai suatu indikator yang dapat menggambarkan perkembangan pembangunan manusia secara terukur dan representati (Sanggelorang, 2015). Secara singkatnya Indeks pembangunan manusia (IPM) atau Human Development Index (HDI) adalah indikator untuk mengukur kualitas (derajat perkembangan manusia) dari hasil pembangunan ekonomi (Astri, 2013).

IPM adalah salah satu hal yang mendasari pembangunan untuk mencapai kesejahteraan manusia sebagai tujuan akhir pembangunan (Meylina, 2013). IPM memberi wawasan pembangunan yang lebih luas karena pembentukannya didesain untuk memfokuskan perhatian pada aspek pembangunan kesehatan, pendidikan dan daya beli sehingga bisa mengetahui perbandingan kinerja pembangunan manusia antar negara maupun antar daerah (Kuncoro, 2013).

Dalam pengukuran indikator Indeks Pembangunan Manusia menggunakan dua metode yaitu (BPS, 2019):

a. Metode lama (1990)

- Kesehatan : Angka harapan hidup saat lahir (AHH)

- Pendidikan : Angka melek huruf (AMH) dan Rata-rata lama sekolah (RLS) yaitu umur 15+ tahun 
- Standar Hidup : PDB per kapita dengan 27 komoditas PPP

- Agregasi Indeks : Rata-rata hitung IPM $=\frac{1}{3} I_{\text {Kesehatan }}+I_{\text {Pengetahuan }}+I_{\text {Pendapatan }} \times 100$

b. Metode Baru (2010)

- Kesehatan : Angka harapan hidup saat lahir (AHH)

- Pendidikan : Harapan lama sekolah (HLS) dan Rata-rata lama sekolah (RLS) yaitu umur 25+ tahun

- Standar Hidup : PNB per kapita dengan 96 Komoditas PPP

- Agregasi Indeks : Rata-rata Ukur/Geometrik

IPM =

$\sqrt[3]{I_{\text {Kesehatan }}+I_{\text {Pengetaluan }}+I_{P_{\text {endapatan }}} \mathrm{x100}}$

\section{Belanja Pemerintah Sektor Kesehatan}

Kesehatan merupakan faktor utama kesejahteraan masyarakat yang hendak diwujudkan pemerintah, maka kesehatan harus menjadi perhatian utama pemerintah sebagai penyelenggara pelayanan publik. Pemerintah harus dapat menjamin hak masyarakat untuk sehat (right for health) dengan memberikan pelayanan kesehatan yang bermutu dan merata, memadai, terjangkau dan berkualitas (Widodo \& Waridin, 2011). Pemerintah berkomitmen untuk memenuhi alokasi anggaran kesehatan sebesar 5\% dari belanja negara, sebagaimana diamanatkan dalam Undang Undang Nomor 9 tahun 2009 tentang kesehatan (Kemenkeu, 2016).

\section{Belanja Pemerintah Sektor Pendidikan}

Pembangunan bidang pendidikan digapai dengan meningkatkan pemerataan baik akses, kualitas, relevansi dan daya saing. Kemudian alokasi anggaran fungsi pendidikan menunjukan upaya pemerintah dalam memberikan pelayanan kepada masyarakat dalam bidang pendidikan dan salah satu upaya untuk memenuhi amanat konstitusi bahwa alokasi anggaran pendidikan sekurang-kurangnya 20\% dari belanja Negara (Kemenkeu, 2016).

\section{Belanja Pemerintah Sektor Ekonomi}

Salah satu perangkat yang selama ini banyak digunakan oleh pemerintah untuk mewujudkan peran tersebut adalah perangkat kebijakan fiskal. Di antara instrument kebijakan fiskal tersebut, ada instrumen dalam bidang pengalokasian dana atau anggaran pembangunan ke bidang yang berkaitan dengan fasilitas publik seperti pendidikan, kesehatan, irigasi, transportasi, dan sebagainya (Kahang, 2016).

\section{Belanja Pemerintah Sektor Perlindungan Sosial}

Dalam UU Nomor 11 tahun 2009 tentang

Kesejahteraan Sosial dijelaskan bahwa Pancasila dan Undang-Undang Dasar Negara Republik Indonesia Tahun 1945 mengamanatkan negara mempunyai tanggung jawab untuk melindungi segenap bangsa Indonesia dan memajukan kesejahteraan sosial serta melindungi masyarakat dari risiko-risiko sosial yang mungkin timbul. Untuk melaksanakan hal tersebut, negara menggunakan Anggaran Pendapatan dan Belanja Negara (APBN) yang dialokasikan dengan tujuan spesifik. Khusus untuk penjaminan kesejahteraan dan perlindungan terhadap risiko sosial, pemerintah memiliki satu pos yang dinamakan bantuan sosial (Bansos) di dalam APBN.

\section{Kerangka Konseptual}

Adapun kerangka konseptual didalam penelitian ini adalah sebagai berikut:

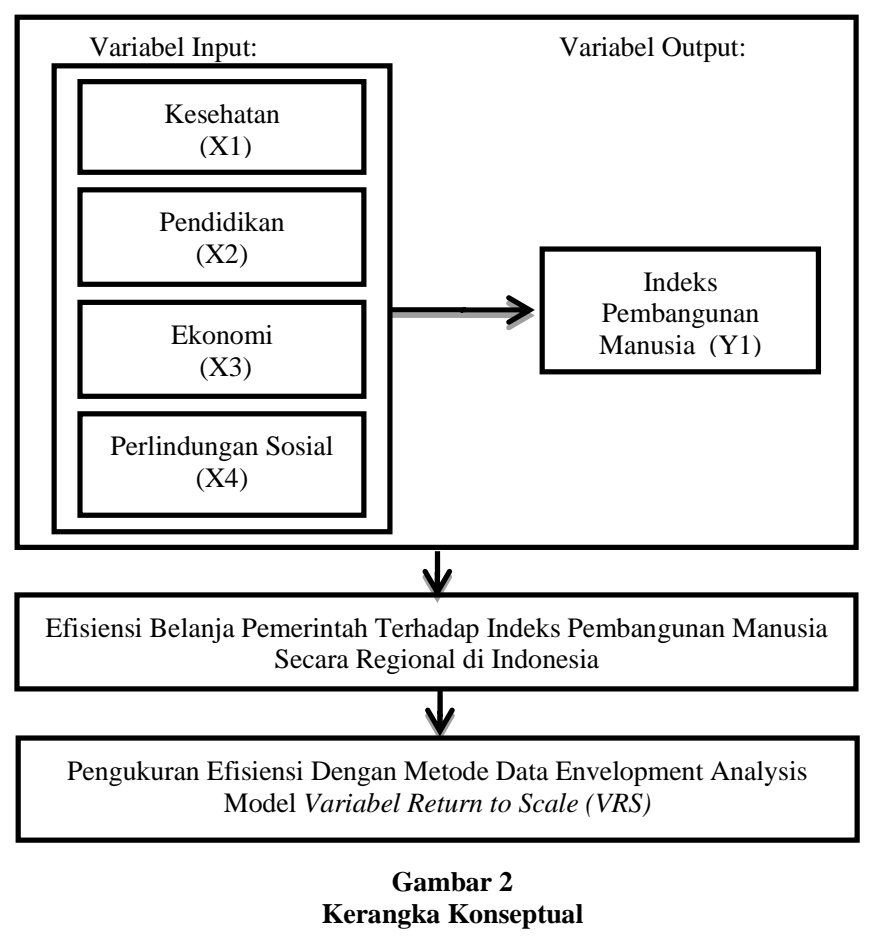

Hipotesis

Hipotesis ini merupakan jawaban sementara terhadap masalah penelitian yang kebenarannya masih harus diuji ecara empiris. Berdasarkan latar belakang masalah dan uraian pada penelitian terdahulu, tujuan penelitian, landasan teori dan telah dituangkan dalam kerangka pemikiran, maka deapat ditarik hipotesis sebagai berikut: 
$\mathrm{H}_{0}$ : Tidak terdapat perbedaan tingkat efisiensi belanja pemerintah terhadap indeks pembangunan manusia secara regional di Indonesia.

$\mathrm{H}_{\mathrm{a}}$ : Terdapat perbedaan tingkat efisiensi belanja pemerintah terhadap indeks pembangunan manusia secara regional di Indonesia.

\section{METODE PENELITIAN Jenis dan Sumber Data}

Adapun jenis data yang digunakan dalam penelitian ini adalah data sekunder yang berbentuk data panel yaitu data gabungan dari data time series dan data cross section, dimana unit cross section yang sama diukur pada waktu yang berbeda. Maka dengan kata lain, data panel merupakan data dari beberapa individu sama yang diamati dalam kurun waktu tertentu. Data didalam penelitian ini merupakan data panel dari 34 provinsi di Indonesia dengan variabel input adalah belanja pemerintah bidang kesehatan, pendidikan, ekonomi, perlindungan sosial dan variabel ouput adalah indeks pembangunan manusia berbentuk data tahunan yang dimulai dari tahun 2014 hingga tahun 2018. Sedangkan sumber data dalam penelitian ini berasal dari Publikasi Kementerian Keuangan RI secara online.

\section{Definisi Operasionalisasi Variabel}

Dalam melakukan penelitian diperlukan menentukan karakter yang akan diteliti yang biasanya dikenal dengan variabel. Variabel merupakan gambaran nyata mengenai fenomenafenomena penelitian. Operasional variabel adalah petunjuk tentang bagaimana cara mengukur suatu variabel dalam penelitian. Dalam penelitian ini terdapat dua variabel yaitu terikat (Dependen) dan variabel bebas (Independen).

\section{Variabel Dependent (Y)}

Indeks pembangunan manusia (Y) adalah alat ukur kesejahteraan suatu negara yang dilihat dari kesehatan, pendidikan dan pendapatan. Dalam satuan persen $(\%)$.

\section{Variabel Independent $(\mathbf{X})$}

a. Belanja Pemerintah Bidang Pendidikan $\left(\mathrm{X}_{1}\right)$ adalah mempunyai peranan penting dalam menujang SDM unggul. Dalam satuan miliar rupiah $(\mathrm{Rp})$.

b. Belanja Pemerintah Bidang Kesehatan $\left(\mathrm{X}_{2}\right)$ adalah Investasi publik di bidang kesehatan bertujuan untuk memberikan kesempatan pelayanan kesehatan yang lebih merata kepada masyarakat sehingga sumber daya manusia (SDM) handal yang sehat menjadi semakin bertambah. Dalam satuan miliar rupiah (Rp).

c. Belanja Pemerintah Bidang Ekonomi $\left(\mathrm{X}_{3}\right)$ adalah anggaran yang dikeluarkan pemerintah untuk sarana dan prasarana dalam memenuhi kebutuhan ekonomi agar masyarakat memiliki standar hidup yang layak dalam memenuhi kebutuhannya. Dalam satuan miliar rupiah $(\mathrm{Rp})$.

d. Belanja perlindungan sosial $\left(\mathrm{X}_{4}\right)$ adalah anggaran yang dikeluarkan oleh pemerintah untuk melindungi masyarakat dari kemungkinan terjadinya risiko sosial, meningkatkan kemampuan ekonomi, dan kesejahteraan masyarakat. Dalam satuan miliar rupiah $(\mathrm{Rp})$.

\section{Metode Analisis Data}

Dalam pengukuran efisiensi dengan menggunakan DEA terdapat dua model yang sering digunakan, yaitu Constant Return to Scale (CRS) dan Variable Return to Scale (VRS). Model CRS sering juga dikenal dengan sebutan model CCR sebagai singkatan dari para ahli yang mengemukakan model tersebut ialah Charnes, Cooper, dan Rhodes. Dalam model CRS setiap Unit Kegiatan Ekonomi (UKE) atau Decision Making Unit (DMU) akan dibandingkan dengan seluruh DMU yang ada di sampel dengan asumsi bahwa kondisi internal dan eksternal DMU adalah sama. Kritik terhadap asumsi ini adalah bahwa asumsi CRS hanya sesuai untuk kondisi dimana seluruh DMU beroperasi pada skala optimal. Namun, dalam kenyataannya meskipun DMU tersebut beroperasi dengan sumber daya (input) yang sama dan menghasilkan output yang sama pula tetapi kondisi internal dan eksternalnya mungkin berbeda sehingga dapat mengakibatkan sebuah DMU tidak beroperasi pada skala optimal. Menurut Charnes, Cooper, dan Rhodes model ini dapat menunjukkan technical efficiency secara keseluruhan atau nilai dari profit efisiensi untuk setiap DMU.

Terdapat dua orientasi pengukuran dalam metode analisis DEA, yaitu orientasi input dan orientasi output. Pengukuran yang berorientasi pada input menunjukkan sejumlah input dapat dikurangi secara proporsional tanpa mengubah jumlah output yang dihasilkan dengan berdasarkan jumlah output yang telah dihasilkan. Dengan menggunakan model berorientasi input, maka model tersebut akan menghitung pengurangan input yang diperlukan 
untuk menghasilkan kinerja yang efisien dengan output yang tetap.

Metode VRS adalah kebalikan dan metode CRS yaitu tidak ada hubungan linear antara input dan output. Setiap penambahan input tidak menghasilkan ouput yang proporsionalnya sehingga sehingga efisiensinya bisa saja naik atau turun. Persamaan metode dari model ini adalah sebagai berikut:

Dalam penelitian ini, dimana terdapat tiga model berdasarkan asumsi VRS.

Model 1. sesuai dengan versi sebenarnya dari dengan rangkaian indikator input dan output terpilih yang sesuai, memaksimalkan.

$$
\begin{aligned}
& \begin{array}{l}
\text { maximize } \\
\text { subject to }
\end{array} \\
& -X_{0 i}+\sum_{k=1}^{S} X_{k i} \lambda_{k} \leq 0, \quad i=1,2, \ldots, n, \\
& -Y_{0 j} \Omega_{0}+\sum_{k=1}^{S} Y_{k j} \lambda_{k} \geq 0, \quad j=1,2, \ldots, m, \\
& \sum_{k=1}^{S} \lambda_{k}=1 . \\
& \lambda_{k} \geq 0, \quad k=1,2, \ldots, S,
\end{aligned}
$$

Model 2. dalam produksi output setiap negara hanya menggunakan satu input, aparatus pengambilan keputusan ekonomi makro, birokrasi yang secara kolektif disebut sebagai juru mudi. Dan setiap negara menggunakan satu nakhoda. Jadi $\mathrm{Xk}=1$, untuk semua

$\mathrm{k}=1,2, \ldots, \mathrm{S}$. Model yang sepadan demikian

maximize $\Omega_{0}$

subject to

$$
\begin{aligned}
& -Y_{0 j} \Omega_{0}+\sum_{k=1}^{S} Y_{k j} \lambda_{k} \geq 0, \quad j=1,2, \ldots, m, \\
& \sum_{k=1}^{S} \lambda_{k}=1 \\
& \lambda_{k} \geq 0, \quad k=1,2, \ldots, S,
\end{aligned}
$$

Di versi ini, kendala input $-X 0 i+\sum_{k=1}^{s} \mathrm{Xki} \lambda \mathrm{k} \leq$ $0, \mathrm{i}=1,2, \ldots \mathrm{n}$ menjadi $-X 0 i=\sum_{k=1}^{s}$ Xki $\chi \mathrm{k} \leq 0$, $\mathrm{i}=1,2, \ldots \mathrm{n}$ dan dikkurangi menjadi $\sum_{k-1}^{s} \alpha \mathrm{k} \leq 1$ yang redun dan sejak di bawah VRS $\sum_{k-1}^{s} \alpha \mathrm{k} \leq 1$

Model 3. istilah seperti "input" dan "output" sebagian besar bersifat generik. Kinerja yang tidak diinginkan atribut dianggap input dan kinerja atribut yang diinginkan (seperti pertumbuhan ekonomi) dianggap output. Dengan demikian, variabel input dan output dalam model 3 mewakili atribut yang tidak diinginkan dan diinginkan masing-masing. Dalam menggunakan DEA, ada beberapa hal yang perlu diperhatikan yaitu posityvity, jumlah DMU, homogeneity, isotonicity, windows analysis dan bobotnya. Sebagai metode yang menggunakan metode linear, maka DEA memiliki ketentuan bahwa hasil dari infut dan outputnya harus bernilai positif $(>0)$.

Dimana

$\Omega 0=$ Efisiensi DMU pada CRS

$\mathrm{N}=$ Jumlah DMU

$\mathrm{M} \quad$ = Jumlah input

$\mathrm{S} \quad=$ Jumlah output

Xkí = Jumlah input ke-i DMU j

Ykj = Jumlah input ke-i DMU j

$\lambda_{\mathrm{k}} \quad=$ Bobot DMU j untuk DMU yang dihitung

Pada model CRR atau yang disebut CRS terdapat syarat convexity constraint, berberda dengan model Variabel Retrun to Scale (VRS) yang terdapat syarat convexity constraint.

\section{HASIL PENELITIAN DAN PEMBAHASAN}

\section{Hasil Penelitian}

Berdasarkan hasil dari pengolahan data dengan menggunakan metode analisis DEA selama tahun 2014-2018, dengan menggunakan pendekatan Variabel Retrun to Scale (VRS) yang berorientasi pada Input dengan peralatan software DEAP versi 2.1 untuk melihat nilai Efisien Belanja Pemerintah Terhadap Indeks Pembangunan Manusia Secara Regional di Indoensia. Adapun nilai yang dikatakan efisien ditunjukan oleh angka 1,000 atau $100 \%$ jika dibawah rata-rata maka DMU tersebut dinyakatan tidak efisien. Berdasarkan hasil perhitungan efisiensi menggunakan DEA, tingkat efisiensi belanja pemerintah terhadap indeks pembangunan manusia secara regional di Indonesia diperoleh hasil sebagai berikut.

Tabel 1

Efisiensi Belanja Pemerintah Terhadap Indeks Pembangunan Manusia Secara Regional di Indonesia, 2014-2018 (VRS-Input Oriented)

\begin{tabular}{|c|l|c|c|c|c|c|}
\hline \multirow{2}{*}{ No } & \multicolumn{2}{|c}{ Provinsi } & \multicolumn{5}{|c|}{ Tahun } \\
\cline { 2 - 7 } & & $\mathbf{2 0 1 4}$ & $\mathbf{2 0 1 5}$ & $\mathbf{2 0 1 6}$ & $\mathbf{2 0 1 7}$ & $\mathbf{2 0 1 8}$ \\
\hline $\mathbf{1}$ & Aceh & 0.704 & 0.726 & 0.753 & 0.775 & 0.748 \\
\hline $\mathbf{2}$ & Sumatera Utara & 0.491 & 0.487 & 1.000 & 1.000 & 0.892 \\
\hline $\mathbf{3}$ & Sumatera Barat & 0.860 & 0.877 & 0.536 & 0.527 & 0.703 \\
\hline $\mathbf{4}$ & Riau & 1.000 & 1.000 & 1.000 & 1.000 & 1.000 \\
\hline $\mathbf{5}$ & Jambi & 1.000 & 1.000 & 1.000 & 1.000 & 1.000 \\
\hline $\mathbf{6}$ & Sulawesi Selatan & 0.414 & 0.407 & 0.842 & 1.000 & 0.707 \\
\hline $\mathbf{7}$ & Bengkulu & 0.057 & 0.884 & 1.000 & 1.000 & 1.000 \\
\hline $\mathbf{8}$ & Lampung & 1.000 & 0.926 & 0.814 & 0.979 & 0.808 \\
\hline $\mathbf{9}$ & Bangka Belitung & 0.126 & 0.302 & 0.707 & 0.842 & 1.000 \\
\hline $\mathbf{1 0}$ & Kepulauan Riau & 1.000 & 1.000 & 1.000 & 1.000 & 1.000 \\
\hline $\mathbf{1 1}$ & DKI Jakarta & 1.000 & 1.000 & 1.000 & 1.000 & 1.000 \\
\hline $\mathbf{1 2}$ & Jawa Barat & 0.195 & 1.000 & 0.417 & 0.591 & 0.406 \\
\hline $\mathbf{1 3}$ & Jawa Tengah & 0.225 & 1.000 & 0.501 & 0.535 & 0.331 \\
\hline $\mathbf{1 4}$ & DI Yogyakarta & 1.000 & 1.000 & 1.000 & 1.000 & 1.000 \\
\hline
\end{tabular}




\begin{tabular}{|l|l|l|l|l|l|l|}
\cline { 2 - 3 } $\mathbf{1 5}$ & Jawa Timur & 0.267 & 0.297 & 0.218 & 0.192 & 0.879 \\
\hline $\mathbf{1 6}$ & Banten & 1.000 & 1.000 & 1.000 & 1.000 & 0.990 \\
\hline $\mathbf{1 7}$ & Bali & 1.000 & 1.000 & 1.000 & 1.000 & 1.000 \\
\hline $\mathbf{1 8}$ & Nusa Tenggara Barat & 0.763 & 0.831 & 0.744 & 0.819 & 0.782 \\
\hline $\mathbf{1 9}$ & Nusa Tenggara Timur & 0.409 & 1.000 & 0.962 & 0.869 & 0.903 \\
\hline $\mathbf{2 0}$ & Kalimantan Barat & 1.000 & 1.000 & 0.998 & 0.930 & 0.863 \\
\hline $\mathbf{2 1}$ & Kalimantan Tengah & 0.805 & 0.466 & 0.526 & 0.769 & 0.844 \\
\hline $\mathbf{2 2}$ & Kalimantan Selatan & 0.876 & 0.897 & 0.710 & 0.738 & 0.674 \\
\hline $\mathbf{2 3}$ & Kalimantan Timur & 1.000 & 1.000 & 1.000 & 1.000 & 1.000 \\
\hline $\mathbf{2 4}$ & Kalimantan Utara & 1.000 & 1.000 & 1.000 & 1.000 & 1.000 \\
\hline $\mathbf{2 5}$ & Sulawesi Utara & 1.000 & 0.929 & 0.824 & 0.760 & 0.725 \\
\hline $\mathbf{2 6}$ & Sulawesi Tengah & 0.636 & 1.000 & 1.000 & 1.000 & 1.000 \\
\hline $\mathbf{2 7}$ & Sulawesi Selatan & 0.474 & 0.408 & 0.842 & 1.000 & 0.707 \\
\hline $\mathbf{2 8}$ & Sulawesi Tenggara & 0.751 & 0.490 & 0.498 & 0.580 & 1.000 \\
\hline $\mathbf{2 9}$ & Gorontalo & 1.000 & 0.615 & 0.751 & 0.728 & 0.849 \\
\hline $\mathbf{3 0}$ & Sulawesi Barat & 0.105 & 0.919 & 0.866 & 1.000 & 1.000 \\
\hline $\mathbf{3 1}$ & Maluku & 0.656 & 0.311 & 0.391 & 1.000 & 1.000 \\
\hline $\mathbf{3 2}$ & Maluku Utara & 0.877 & 0.518 & 0.544 & 0.668 & 0.635 \\
\hline $\mathbf{3 3}$ & Papua Barat & 0.679 & 0.304 & 0.391 & 0.440 & 0.497 \\
\hline $\mathbf{3 4}$ & Papua & 0.364 & 0.172 & 0.200 & 0.212 & 0.264 \\
\hline $\mathbf{S}$ & & & & & \\
\hline
\end{tabular}

Sumber : Data diolah, 2020

Berdasarkan dari hasil pengujian dengan menggunakan aplikasi DEAP versi 2.1 dengan menggunakan Variabel Retrun to Scale (VRS), menunjukan bahwa Provinsi yang mengalami efisien dari tahun 2014-2018 ada 14 Provinsi diantaranya yaitu Riau, Jambi, Bengkulu, Bangka Belitung, Kepulauan Riau, DKI Jakarta, DI Yogyakarta, Bali, Kalimantan Timur, Kalimantan Utara, Sulawesi Tengah, Sulawesi Tenggara, Sulawesi Barat dan Maluku. Sedangkan provinsi yang mengalami inefisien ada 20 provinsi diantaranya yaitu Aceh, Sumatera Utara, Sumatera Barat, Sulawesi Selatan, Lampung, Jawa Barat, Jawa Tengan, Jawa Timur, Banten, Nusa Tenggara Barat, Nusa Tenggara Timur, Kalimantan Barat, Kalimantan Tengah, Kalimantan Selatan, Sulawesi Utara, Sulawesi Selatan, Gorontalo, Maluku Utara, Papua Barat dan Papua. Dari provinsi yang tidak efisien penulis membagi lagi kepada 3 bagian sebagai berikut.

1. Inefisiensi dengan nilai skor (0,8000,999), ditentukan oleh beberapa provinsi diantaranya Sumatera Utara, Lampung, Jawa Timur, Banten, Nusa Tenggara Timur, Kalimantan Barat, Kalimantan Tengah dan Gorontalo.

2. Inefisiensi dengan nilai skor (0,5000,799), ditentukan oleh beberapa provinsi diantaranya Aceh, Sumatera Barat, Sulawesi Selatan, Nusa Tenggara Barat,
Kalimantan Selatan, Sulawesi Utara, Sulawesi Selatan dan Maluku Utara.

3. Inefisiensi dengan nilai skor $(0,000-0,499)$, ditentukan oleh beberapa provinsi diantaranya Jawa Barat, Jawa Tengah, Papua Barat dan Papua.

Penulis juga mencamtumkan provinsi yang setiap tahunnya memperbaiki tingkat skor efisiensinya di antaranya yaitu :

1. Bengkulu dengan skor efisiensinya 0.057 ditahun 2014, pada tahun 2015 skor provinsi Bengkulu meningkat menjadi 0.884, pada tahun 2016-2018 skor provinsi Bengkulu berhasil mencapai nilai skor efisien yaitu dengan skor 1.000.

2. Bangka Belitung dengan skor efisiensinya 0.126 ditahun 2014, pada tahun 2015 skor provinsi Bangka Belitung meningkat menjadi 0.302, pada tahun 2016 skor provinsi Bangka Belitung meningkat menjadi 0.707, pada tahun 2017 skor provinsi Bangka Belitung meningkat menjadi 0.842, pada tahun 2018 skor provinsi Bangka Belitung berhasil mencapai nilai skor efisien yaitu dengan skor 1.000 .

3. Sulawesi Tengah dengan skor efisiensinya 0.636 ditahun 2014, pada tahun 2015-2018 skor provinsi Sulawesi Tengah berhasil mencapai nilai skor efisien yaitu dengan skor 1.000 .

4. Sulawesi Tenggara dengan skor efisiensinya 0.751 ditahun 2014, pada tahun 2015 skor provinsi Sulawesi Tenggara menurun menjadi 0.490,pada tahun 2016 skor provinsi Sulawesi Tenggara meningkat menjadi 0.498, pada tahun 2017 skor provinsi Sulawesi Tenggara meningkat menjadi 0.580, pada tahun 2018 skor provinsi Sulawesi Tenggara berhasil mencapai nilai skor efisien yaitu dengan skor 1.000 .

5. Sulawesi Barat dengan skor efisiensinya 0.105 ditahun 2014, pada tahun 2015 skor provinsi Sulawesi Barat meningkat menjadi 0.919,pada tahun 2016 skor provinsi Sulawesi Barat menurun menjadi 0.866, pada tahun 2017-2018 skor provinsi Sulawesi Barat berhasil mencapai nilai skor efisien yaitu dengan skor 1.000.

6. Maluku dengan skor efisiensinya 0.656 ditahun 2014, pada tahun 2015 skor provinsi Malukumenurun menjadi 0.311,pada tahun 2016 skor provinsi Maluku meningkat menjadi 0.391, pada tahun 2017-2018 skor 
provinsi Maluku berhasil mencapai nilai skor efisien yaitu dengan skor 1.000.

Tujuannya adalah untuk melihat provinsiprovinsi yang sudah efisien maupun yang belum efisien dalam menggunakan anggaran pemerintah untuk peningkatan nilai IPM, dan juga untuk melihat provinsi-provinsi yang jauh ketinggalan tingkat efisiensinya apakah karena terlalu berlebihan dalam menggunakan anggaran tapi IPM nya rendah sehingga provinsi yang tidak efisien dapat memperbaiki kinerjanya dalam memanfaatkan belanja pemerintah apakah ditambah atau dikurangi untuk peningkatan IPM.

\section{Pembahasan}

Berikut ini adalah pembahasan mengenai input pada belanja pemerintah terhadap indeks pembangunan manusia secara regonal di Indonesia yang belum efisien dalam memanfaatkan belanja pemerintah baik sektor pendidikan, kesehatan, ekonomi dan perlindungan sosial dalam meningkatkan nilai IPM yang terdiri dari 20 Provinsi, salah satunya Provinsi Aceh. Adapun untuk memperoleh nilai efisien perlu tentunya memperbaiki capaian jumlah input yang digunakan maupun tingkat capaian outputnya. Untuk pembahasan ini penulis akan membahas dari capaian skor $(0,999$ - 0,000), salah satunya Provinsi Aceh yaitu sebagai berikut:

\section{Aceh}

Berikut dapat dilihat pada tabel 2 pada provinsi Aceh belum mencapai skala yang efisien, dikarenakan penggunaan input yang belum optimal, sehingga menyebabkan output yang dihasilkan juga belum optimal.

Tabel 2

Nilai Original,Target, Radial Movement, dan Slack Movement

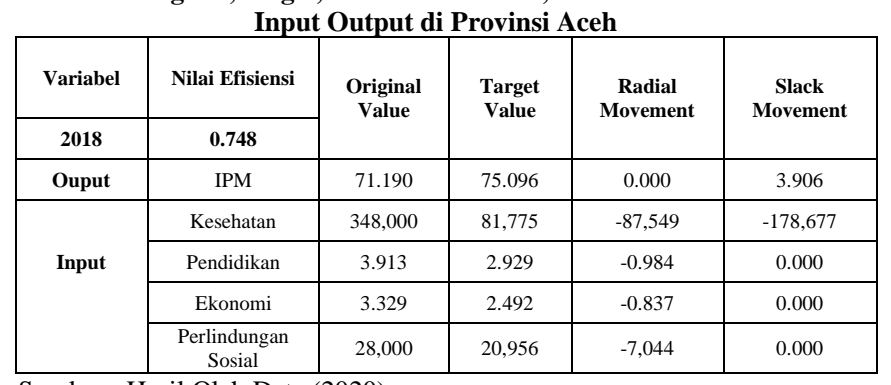

Sumber : Hasil Olah Data (2020)

Pada tabel 2 di atas dapat dilihat bahwa nilai skorProvinsi Aceh adalah 0.748 dimana nilai ini dibawah skor 1. Bermakna bahwa Provinsi Aceh belum lagi efisien dalam memberikan hasil Indeks Pembangunan Manusia. Supaya efisien Provinsi Aceh perlu menambahkan skor sebesar $1-0.748=0,252$. Untuk mencapai tambahan nilai skor 0,252 Provinsi Aceh harus memperbaiki input belanja pemerintah bidang kesehatan, pendidikan, ekonomi dan perlindungan sosial.

Untuk mengatasi inefisien pada input belanja pemerintah bidang kesehatan, Provinsi Acehharus mengurangi belanja pemerintah bidang kesehatan sebesar 348,000-81,775 $=266,225$ atau (266 Miliar), hal ini juga dapat dibuktikan dengan menambahkan nilai radial movement dengan nilai slack movement, maksudnya ada sejumlah 266 Miliar belanja pemerintah bidang kesehatan yang tidak dimanfaatkan secara optimal sehingga dalam pengelolaan tidak efisien.

Adapun pada input belanja pemerintah bidang pendidikan, Provinsi Acehharus mengurangi belanja pemerintah bidang pendidikan sebesar 3.913-2.929 $=0.984$ Miliar, hal ini juga dapat dilihat pada besaran radial movement, maksudnya ada sejumlah 0.984 Miliar belanja pemerintah bidang pendidikan yang tidak dimanfaatkan secara optimal sehingga dalam pengelolaan tidak efisien.

Kemudian pada input belanja pemerintah bidang ekonomi, Provinsi Aceh harus mengurangi belanja pemerintah bidang ekonomi sebesar 3.329$2.492=0.837$ Miliar, hal ini juga dapat dilihat pada besaran radial movement, maksudnya ada sejumlah 0.837 Miliar belanja pemerintah bidang ekonomi yang tidak dimanfaatkan secara optimal sehingga dalam pengelolaan tidak efisien.

Sedangkan pada input belanja pemerintah bidang perlindungan sosial, Provinsi Aceh harus mengurangi belanja pemerintah bidang perlindungan sosial sebesar 28,000-20,956 = 7,044 atau ( 7 Miliar), hal ini juga dapat dilihat pada besaran radial movement, maksudnya ada sejumlah 7 Miliar belanja pemerintah bidang perlindungan sosial yang tidak dimanfaatkan secara optimal sehingga dalam pengelolaan tidak efisien.

\section{KESIMPULAN DAN SARAN Kesimpulan}

Setiap provinsi di Indonesia dikatakan efisien secara teknis jika mampu menggunakan input (Belanja Pemerintah) seminimal mungkin untuk memperoleh output nilai IPM yang tinggi. Dari 34 provinsi di Indonesia yang diteliti, ada 14 provinsi yang mengalami efisien diantaranya yaitu Riau, Jambi, Bengkulu, Bangka Belitung, Kepulauan Riau, DKI Jakarta, DI Yogyakarta, Bali, Kalimantan Timur, Kalimantan Utara, Sulawesi Tengah, Sulawesi Tenggara, Sulawesi Barat dan Maluku. Sedangkan provinsi yang mengalami inefisien ada 20 provinsi diantaranya yaitu Aceh, Sumatera Utara, Sumatera Barat, Sulawesi Selatan, 
Lampung, Jawa Barat, Jawa Tengan, Jawa Timur, Banten, Nusa Tenggara Barat, Nusa Tenggara Timur, Kalimantan Barat, Kalimantan Tengah, Kalimantan Selatan, Sulawesi Utara, Sulawesi Selatan, Gorontalo, Maluku Utara, Papua Barat dan Papua.

\section{Saran}

Berdasarkan hasil penelitian yang telah disimpulkan diatas, maka dapat dikemukakan beberapa saran sebagai berikut:

1. Diharapkan kepada seluruh provinsi khusunya kepada yang inefisien agar dapat memperbaiki kinerjanya dalam penggunaan anggaran (Belanja Pemerintah) yang sudah digunakan dalam meningkatan nilai IPM.

2. Diharapkan kepada pemerintah agar dapat melakukan pengambilan keputusan atau kebijakan dalam permasalahan pencapaian nilai IPM setiap provinsi di Indonesia.

\section{DAFTAR PUSTAKA}

Arifin, M. Y. (2015). Pengaruh Pengeluaran Pemerintah Sektor Kesehatan, Pengeluaran Pemerintah Sektor Pendidikan dan Pertumbuhan Ekonomi Terhadap Indeks Pembangunan Manusia Jawa Timur 2006-2013. Retrieved from http://repository.unej.ac.id/handle/12345 $\underline{6789 / 65501}$

Astri, M., Nikensari, S. I., \& W., D. H. K. (2013). Pengaruh Pengeluaran Pemerintah Daerah pada Sektor Pendidikan dan Kesehatan terhadap Indeks Pembangunan Manusia di Indonesia. Jurnal Pendidikan Ekonomi Dan Bisnis, 1(1), 77-102. https://doi.org/10.1021/acs.jpcc.7b022

Badan Pusat Statistik, 2017. Indeks Pembangunan Manusia. Jakarta: BPS Indonesia.

Badan Pusat Statistik, 2019. Indeks Pembangunan Manusia. Jakarta: BPS Indonesia.

Danu, A., \& Zuhdi, U. (2013). The Government Expenditure Efficiency towards the Human Development. Procedia Economics and Finance, 5(2012), 615622. $\quad$ https://doi.org/10.1016/S22125671(13)00072-5.
Kahang, M., Saleh, M., \& Suharto, R. B. (2016). Pengaruh Pengeluaran Pemerintah Sektor Pendidikan dan Kesehatan terhadap Indeks Pembangunan Manusia di Kabupaten Kutai Timur. Jurnal Ekonomi, Manakemen Dan Akuntansi, 18(2), 130-140. https://doi.org/10.1007/BF03173680

Kementrian Keuangan, 2016. Alokasi Anggaran Belanja Pemerintah Pusat Jakarta: Kemenkeu Indonesia.

Mauriza, S., Hamzah, A. B., \& Syechalad, M. N. (2013). Analisis Indeks Pembangunan Manusia di Kawasan Barat dan Kawasan Timur Propinsi Aceh. Pascasarjana Universitas Syiah Kuala, 15(2), 29-43. Retrievedfrom.http://prodipps.unsyiah.ac.i d/Jurnalmie/images/Jurnal/2.vol1.no2/4.29 43.sazli.mauriza.pdf

Said, F. (2014). Assessing Macroeconomic Performance of OIC Member Countries Using Data Envelopment Analysis, DEA, (January 2011).

Todaro, Michael P. 2000. Pembangunan Ekonomi di Dunia Ketiga. Erlangga. Jakarta

Widodo, A., \& Waridin. (2011). Analisis Pengaruh Pengeluaran Pemerintah di Sektor Pendidikan dan Kesehatan Terhadap Pengentasan Kemiskinan Melalui Peningkatan Pembangunan Manusia di Provinsi Jawa Tengah. Jurnal Dinamika Ekonomi Pembangunan, 1(1), 25-42. https://doi.org/10.1109/IROS.2010.564987 0.

Zhang, H., Song, W., Peng, X., \& Song, X. (2012). Evaluate the Investment Efficiency by Using Data Envelopment Analysis: The Case of China, 2012(June), 174-182. 